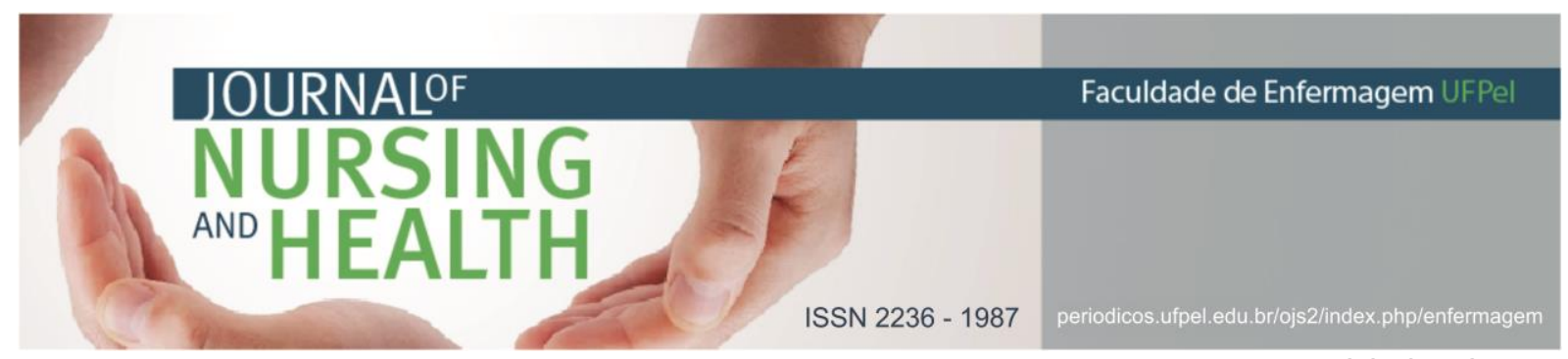

ARTIGO ORIGINAL

\title{
A participação da família na reabilitação psicossocial do sujeito em sofrimento psíquico
}

\author{
Family involvement in psychosocial rehabilitation of individuals under psychological \\ suffering
}

La participación de la familia en la rehabilitación psicosocial del individuo en sufrimiento psíquico

Carvalho, Andreia dos Santos ${ }^{1}$; Machado, Viviane Medeiros²; Maagh, Samanta Bastos ${ }^{3}$; Dos Santos, Alessandro Marques ${ }^{4}$; Guedes, Ariane da $\mathrm{Cruz}^{5}$; Fávero, Fabrine Maria ${ }^{6}$; Fávero, Débora Cristina ${ }^{7}$

\section{RESUMO}

Objetivo: conhecer a participação da família na reabilitação psicossocial do sujeito em sofrimento psíquico. Métodos: trata-se de uma pesquisa qualitativa, exploratória e descritiva, realizada em 2012. Os sujeitos do estudo foram seis familiares de usuários de um Centro de Atenção Psicossocial (CAPS). Foi utilizada a análise temática conforme Minayo, que tem como foco encontrar núcleos de sentido na comunicação apresentada pelo material estudado. Resultados: emergiram desse estudo dois eixos temáticos: A inserção do sujeito em sofrimento psíquico na sociedade sob a ótica da família e A participação da família na reabilitação psicossocial do sujeito em sofrimento psíquico. Conclusão: há um certo isolamento do usuário no serviço substitutivo. É importante que os profissionais de saúde invistam na autonomia dos sujeitos, contribuindo para o conhecimento do usuário e sua família acerca dos seus direitos e da proposta da reforma psiquiátrica. Colaborando com o aumento do compromisso da família neste processo.

Descritores: Saúde mental; Família; Desinstitucionalização; Serviços de saúde mental.

\section{ABSTRACT}

Objective: to now the family's participation in psychosocial rehabilitation of the individual under psychological distress. Methods: this is a qualitative, exploratory and descriptive study, held in 2012. The study subjects were relatives of individuals with psychological distress, users of a Psychosocial Care Center (CAPS). The thematic analysis according to Minayo was used, whose focus is to find nuclei of meaning in the communication presented by material studied. Results: this study emerged the themes: The insertion of the subject in psychological distress in society from the perspective of the family and the family's participation in psychosocial rehabilitation of the subject

\footnotetext{
${ }^{1}$ Enfermeira. Graduação em Enfermagem. Enfermeira no Hospital Universitário São Francisco de Paula. Pelotas, RS, Brasil. E-mail: andreia.carvalho1985@yahoo.com.br

2 Enfermeira. Graduada em Enfermagem pela Universidade Católica de Pelotas. Pelotas, RS, Brasil. E-mail: vivimachad@bol.com.br

${ }^{3}$ Enfermeira. Mestre em Ciências. Docente do Centro de Ciências da Saúde da Universidade Católica de Pelotas. Pelotas, RS, Brasil. E-mail: samantamaagh@yahoo.com.br

${ }^{4}$ Enfermeiro. Doutor em Enfermagem. Professor da Universidade Católica de Pelotas. Pelotas, RS, Brasil. E-mail: sandromarquessan@yahoo.com.br

${ }^{5}$ Enfermeira. Doutora em Enfermagem. Professora da Faculdade de Enfermagem da Universidade Federal de Pelotas. Pelotas, RS, Brasil. E-mail: arianecguedes@gmail.com

${ }^{6}$ Acadêmica do curso de graduação em Enfermagem da Universidade Federal da Fronteira Sul. Chapecó, SC, Brasil. E-mail: famenlak@gmail.com

${ }^{7}$ Acadêmica do curso de graduação em Enfermagem da Universidade Federal da Fronteira Sul. Chapecó, SC, Brasil. E-mail: deboracfavero@hotmail.com
} 


\section{NURSING \\ AND

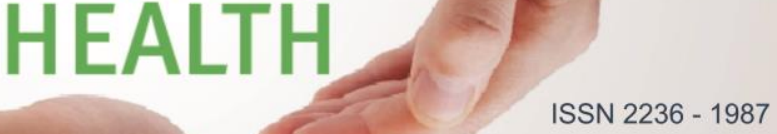

in psychological distress. Conclusions: there's a certain isolation used in substitute service. It is understood that it is important for health professionals bet on education, increasing the user's knowledge and his family about their rights and psychiatric reform proposal. This may collaborate with the commitment of the family in this process. Descriptors: Mental health; Family; Deinstitutionalization; Mental health services.

\section{RESUMEN}

Objetivo: conocer la participación de la familia en la rehabilitación psicosocial del sujeto en la angustia psicológica. Métodos: se trata de un estudio cualitativo, exploratorio y descriptivo, ocurrido en 2012. El análisis temático fue utilizado como Minayo, que se ha centrado en la búsqueda de sentido en la comunicación presentada por el material estudiado. Resultados: el presente estudio surgió los temas: La inserción del sujeto en los trastornos psicológicos en la sociedad desde el punto de vista de la familia y la participación de la familia en la rehabilitación psicosocial del sujeto en la angustia psicológica. Conclusiones: hay un cierto aislamiento de usuario en un servicio sustitutorio. Es importante que los profesionales de la salud aposten en la educación, aumenten el conocimiento del usuario y su familia acerca de sus derechos y la propuesta de reforma psiquiátrica. Esto puede colaborar con el compromiso de la familia en este proceso.

Descriptores: Salud mental; Familia; Desinstitucionalización; Servicios de salud mental.

\section{INTRODUÇÃO}

A Reforma Psiquiátrica no Brasil, idealizada desde o final da década 1970, vem sendo praticada, efetivamente, a partir da instituição da Lei 10.216, em 2001', a qual redireciona o modelo assistencial em saúde mental. Nesse contexto, família passou a ter um papel atuante na reabilitação do indivíduo em sofrimento psíquico, estimulando maior responsabilidade frente ao cuidado, auxiliando na formação de uma rede de atenção integral, que possibilite que o indivíduo estabeleça relações sociais. ${ }^{2}$

Anteriormente ao processo de Reforma Psiquiátrica no Brasil, os indivíduos em sofrimento psíquico eram segregados socialmente e afastados da família, tendo o manicômio como única alternativa de assistência em saúde. E a partir da criação e instituição dos serviços substitutivos ao hospital psiquiátrico, surgiu a ressignificação do cuidado em saúde mental, contemplando a singularidade $\mathrm{e}$ individualidade das pessoas, visando o tratamento em liberdade e a desinstitucionalização.

Nesse sentido, surgiram os Centros de Atenção Psicossocial (CAPS), os quais são considerados serviços estratégicos no cuidado em saúde mental. Esses serviços promovem ações voltadas para participação e colaboração da família, que passam a ser os protagonistas do cuidado. ${ }^{3}$ A Portaria do Ministério da Saúde $n^{\circ} 336$, de 19 de fevereiro de 2002, preconiza a inclusão da família nos CAPS e na reinserção social do usuário, assim como, incluir ações dirigidas para esse público. ${ }^{4}$ Nesse modelo de atenção, os usuários passam a ter maior chance de reinserção social, oposto do que ocorre no modelo hospitalocêntrico, onde a identidade social inexiste e os indivíduos são excluídos de seus direitos e deveres. ${ }^{5}$

Desinstitucionalizar não significa simplesmente retirar os indivíduos da 


\section{JOURNALOF \\ NURSING \\ ${ }^{\text {ANo }}$ HEALTH}

ISSN 2236 - 1987

psíquico seja realizado no âmbito da comunidade. A família pode ser considerada um elo entre o sujeito e a sociedade, com vistas a inseri-lo novamente em seu cotidiano social, colaborando com o desenvolvimento de sua autonomia. Diante disso, o objetivo deste estudo foi conhecer a participação da família na reabilitação psicossocial dos usuários de um CAPS de um município da região sul do Brasil.

\section{MATERIAIS E MÉTODOS}

Trata-se de uma pesquisa qualitativa, exploratória e descritiva. Os sujeitos do estudo foram seis familiares de usuários de um CAPS, localizado na região sul do Brasil. Este CAPS foi implantado em 2001, e constitui um serviço de atenção em saúde mental destinado ao atendimento de pessoas com transtornos mentais graves e persistentes, conforme regulamentação do Ministério da Saúde.

Foram critérios para a inclusão neste estudo: ser familiar cuidador do sujeito em sofrimento psíquico usuário do CAPS, residir no respectivo município em estudo e autorizar o uso do gravador na entrevista. Os critérios de exclusão para o familiar foram ter menos que 18 anos e não ser o cuidador direto do usuário.

O projeto foi aprovado pelo Comitê de Ética em Pesquisa da Universidade Católica de Pelotas, sob o registro do parecer 111.362, considerando a Resolução n 196/96 do Ministério da Saúde. ${ }^{10}$ Garantiu-se o anonimato dos entrevistados, o acesso aos dados coletados e o direito de 
desistir a qualquer momento da pesquisa, sem prejuízo pessoal.

As entrevistas ocorreram no período de setembro a novembro de 2012, após o contato com a coordenação da instituição. Foi realizada uma listagem com o nome de todos os usuários do CAPS e foram sorteados seis familiares de forma aleatória, obedecendo aos critérios de inclusão no estudo.

Posteriormente, foi realizado contato com esses familiares, para a apresentação da proposta, esclarecimento do objetivo e o convite para participar da pesquisa.

Foi agendada uma data e um horário para a entrevista, sendo estas realizadas na residência do familiar. Foram utilizadas entrevistas semiestruturadas para responder ao objetivo do estudo. As perguntas realizadas aos familiares indagaram quando o familiar começou a apresentar problemas psiquiátricos, sobre a inserção do familiar na sociedade e seu desenvolvimento no território e se o acompanha e incentiva nessas atividades. Também, questionou-se as dificuldades $e$ as facilidades que esses encontram no cuidado ao seu familiar e se gostaria de comentar algo mais. Salienta-se que as entrevistas foram gravadas em áudio MP3 e transcritas na íntegra.

A organização dos dados obtidos se deu por meio da operacionalização da análise temática, conforme Minayo, as quais têm como foco encontrar núcleos de sentido na comunicação apresentada pelo material estudado, verificando a sua frequência relacionada com o objetivo analítico proposto para o estudo. Para isso, foram desenvolvidas três etapas: préanálise, exploração do material e tratamento dos resultados obtidos e interpretação. ${ }^{11}$

Os dados obtidos foram organizados para a realização de uma análise mais profunda, sendo feita uma leitura flutuante do conjunto das comunicações. $\mathrm{Na}$ segunda etapa, foram buscadas as categorias, que são palavras ou expressões significativas que organizaram o conteúdo das falas. E na última etapa, a partir da organização dos dados, foram realizadas as interpretações, procurando os significados.

Esse processo foi finalizado com o estabelecimento dos eixos temáticos que serão discutidos a seguir, na apresentação dos resultados e discussão. Ressalta-se que a fim de garantir o sigilo da identidade dos participantes, os familiares serão identificados pela letra $F$ de familiar, seguido do número que corresponde à ordem em que foram entrevistados.

\section{RESULTADOS E DISCUSSÃO}

Participaram do estudo seis familiares de sujeitos em sofrimento psíquico usuários do CAPS. Desses, quatro eram do sexo feminino. A idade dos entrevistados variou entre 46 e 70 anos. No que se refere ao grau de parentesco, F1 é mãe, F2 é cunhada, F3 é esposo, F4 é pai, F5 é mãe e F6 é filha.

Mesmo tendo consentido participar da pesquisa, um dos sujeitos não permitiu a realização da entrevista em sua residência, sendo apenas essa realizada nas dependências do CAPS. 


\section{ISSN 2236 - 1987}

A seguir, serão apresentados os eixos temáticos que emergiram do estudo: A inserção do sujeito em sofrimento psíquico na sociedade sob a ótica da família e A participação da família na reabilitação psicossocial do sujeito em sofrimento psíquico.

\section{A inserção do sujeito em} sofrimento psíquico na sociedade sob a ótica da família

Estar inserido na sociedade é organizar uma vida cotidiana capaz de conduzir a uma continuidade, em interação com os outros a sua volta e com o modo de produção da sociedade.

Quando questionados acerca da inserção do seu familiar em sofrimento psíquico na sociedade, todos os entrevistados mencionam as atividades vinculadas ao CAPS, como as viagens e oficinas. Percebeu-se que a maioria dos relacionamentos sociais estão restritos ao espaço institucional, e a inclusão social tem como significado apenas a participação do usuário no serviço, como evidenciam as falas a seguir:

Pouco sai de casa, só sai para ir ao CAPS, pois já levei ela e ensinei o caminho (F3).

Não frequenta nada, ela só sai por obrigação. Está sempre com a porta e com as janelas fechadas, às vezes está um rico sol e chego lá ela está deitada na cama, fazendo crochê, falo mãe vamos abrir essas janelas, mas ela não gosta, gosta mesmo de se isolar. Só vai ao CAPS às sextas-feiras (F6).
Ainda, corroborando com os depoimentos anteriores, percebe-se que um dos usuários possui boa interação quando a atividade envolve o serviço de saúde mental, porém, no domicílio a sociabilidade com os familiares é restrita, e o mesmo permanece a maior parte do tempo isolado:

Ele é participativo mais nas atividades do CAPS, e gosta de estar lá. Participa das festas desenvolvidas no CAPS, participa da associação, já viajou para Porto Alegre, tudo relacionado à saúde mental ele participa. Quando está em casa, ele passa vendo televisão ou escutando radinho no quarto dele (F2).

Os CAPS surgiram como dispositivos para uma assistência adequada e humanizada. Constroem suas atividades centradas no acolhimento e no vínculo, comprometendo-se com a construção dos projetos de inserção social, tendo em vista, os princípios de cidadania e as possibilidades de cada indivíduo em sofrimento psíquico, a fim de reduzir o estigma e promover uma melhor qualidade de vida. ${ }^{12}$

Observou-se durante as entrevistas que os familiares se sentem satisfeitos com a inserção do usuário em um serviço substitutivo no campo da atenção à saúde mental. Ainda, acreditam que frequentar as atividades ligadas ao CAPS por si só, já caracteriza um grande avanço em direção à reinserção social do seu familiar em sofrimento psíquico, quando comparada às vivências anteriores ao surgimento destas instituições na 


\section{ㄱ. \\ ISSN 2236 - 1987}

cidade. Tais observações são visualizadas nas falas a seguir:

Notei que depois que começou a frequentar o CAPS, há doze anos ela tem mais autonomia (F1).

Depois que começou a fazer tratamento no CAPS, nunca mais houve internações (F2).

Salienta-se que alguns familiares mencionaram outras atividades desempenhadas pelos usuários fora do âmbito do serviço de saúde, conforme falas abaixo:

Sai bastante, está sempre na rua, vai ao centro, na casa das amigas, de parentes, na casa do filho que mora perto, só não gosta muito de bailes, onde tem muito barulho (F4).

Ele vai para tudo que é lugar comigo, levo ele na igreja, no centro, onde eu vou ele vai junto (F5).

Foi possível verificar que mesmo com algumas questões relacionadas à não ampliação da rede e das atividades sociais do usuário, a passagem pelo serviço substitutivo trouxe benefícios, pelo fato de que alguns indivíduos conseguiram melhorar sua qualidade de vida e recuperar algumas habilidades que haviam sido perdidas devido à doença, com destaque para o trabalho, o convívio com familiares e as atividades no território como o culto religioso.

Nesse sentido, a reabilitação psicossocial se consolida como uma estratégia que possibilita ao portador de sofrimento psíquico a retomada da autonomia, para que consiga reestabelecer $a$ independência e o convívio social. No entanto, a reabilitação psicossocial será efetiva se houver atividades que estimulem a reinserção do indivíduo na comunidade.

De acordo com uma das familiares, uma das usuárias realiza atividades laborais, conforme fala abaixo:

Ela realiza várias atividades. Quanto $a$ isso não tenho queixas, ela trabalha meio turno em um supermercado, faz academia, participa das atividades do CAPS há doze anos (F1).

Nesse sentido, o F1, ressaltou que sua filha desempenha atividades laborais durante meio turno em um supermercado da cidade. Esse trabalho não estava vinculado ao serviço de reabilitação, portanto, a mesma foi reinserida ao mercado de trabalho com êxito e após este grande avanço, matriculou-se em uma academia, iniciando as atividades físicas, contando com o apoio e a companhia da familiar. Com isso, a usuária está melhorando sua autoestima, recuperando a autonomia e resgatando seu lugar na sociedade.

Vislumbra-se que nos serviços substitutivos se permita a reorganização dos diversos aspectos da história de vida, facilitando a reinserção e o desenvolvimento das potencialidades sociais dos sujeitos. Esses serviços devem acreditar que estes são capazes e reiterar diariamente seus potenciais por meio de formas de reabilitação, de modo que essas condutas resgatem a 


\section{IOURNAIOF

autoconfiança e a autonomia desse público que possui uma história de exclusão e de afastamento dos seus direitos e da sociedade. ${ }^{13}$

\section{A participação da família na reabilitação psicossocial do sujeito em sofrimento psíquico}

Acredita-se que o cuidado no domicílio facilita 0 processo de reinserção social do sujeito em sofrimento psíquico, pois a família é o elo entre este sujeito, a comunidade e os serviços de saúde. Essa relação família e equipe de saúde pode permitir a construção de redes que consideram as dimensões clínica, psicossocial, afetiva e política para o cuidado em saúde mental. ${ }^{14}$

Verificou-se nos relatos que alguns sujeitos deste estudo afirmaram participar e incentivar a reabilitação psicossocial e a reinserção de seu familiar na sociedade, como evidencia as falas a seguir:

Eu incentivo ela muito, faço academia com ela para incentivála, vou aos grupos de familiares acompanho ela no CAPS (F1).

Eu ajudo bastante, convido ela para sair, sempre procuro tirar ela de casa, mas muitas vezes ela diz que não quer sair, prefere ficar em casa, nem nas filhas dela ela vai. A única atividade que ela participa é a do CAPS (F3).

Sempre que saímos eu e minha esposa, convidamos ela, por exemplo, na casa dos parentes (F4).
Eu acompanho as atividades no CAPS, também participo junto para incentivar ele e eu gosto, me sinto muito bem, para mim, é muito bom, me ajuda também (F5).

O papel da família é cuidar, incentivar, estar presente, ser suporte seguro e confiável, pois é no âmbito familiar que os seus integrantes buscam apoio, compreensão e vislumbram possibilidades. A relação da família com a pessoa em sofrimento psíquico por vezes é tensa, mas quando os sintomas decorrentes do transtorno estão controlados, a convivência pode ser harmoniosa, o que enseja entender o ser humano com transtorno mental como ser único dotado de capacidades, e que, apesar de algumas limitações, é capaz de se relacionar e desenvolver atividades. ${ }^{15}$

Sabe-se que a família ao participar do cuidado de seus entes, tem papel determinante no sucesso do tratamento. O domicílio é um espaço em que pessoas com doenças crônicas e outras afecções podem viver com boa qualidade de vida e manter a estabilidade da doença, desde que a família receba orientação e suporte dos serviços de saúde para isso. ${ }^{16}$

Outros

entrevistados relacionaram os cuidados prestados ao usuário no dia a dia, como uma forma de estar incluso no processo de reabilitação e reinserção social de seu familiar, conforme as falas a seguir:

Nós não temos muita
participação. $\quad A \quad$ minha
participação maior é em casa, sou
eu que dou a medicação para ele,
faço o almoço, café, porque esse


tipo de coisa ele não atina, eu que tenho que fazer para ele (F2).

Eu ajudo no que posso, vou lá sempre que posso, às vezes ela está chorosa, converso com ela, ajudo em alguma coisa na lida da casa (F6).

Com o usuário presente na rotina da casa, a família passa a ter novas responsabilidades, tais como acompanhá-lo ao serviço de saúde, contribuir para as suas atividades diárias, dar suporte social, lidar com seu transtorno mental e crises, o que pode representar uma enorme sobrecarga para a família. ${ }^{17}$

Para que a família seja considerada como base do cuidado em saúde mental, é necessário que sejam reconhecidas as dificuldades provenientes da convivência com os indivíduos com sofrimento psíquico, e dessas, principalmente o que se refere aos sentimentos de cada familiar. ${ }^{18}$ É importante que os profissionais de saúde estejam atentos aos sinais que podem levar à sobrecarga familiar, oferecendo suporte e atenção nesse sentido.

Em uma das entrevistas, percebeu-se a sobrecarga que é gerada ao familiar no cuidado ao sujeito em sofrimento psíquico, conforme a fala a seguir:

Cuidando dele eu também adoeci, fico estressada, cansada. Ele não gosta de ficar parado em casa, ele tem que estar sempre na rua, ele acorda de manhã, toma café e se eu não saio com ele, ele sai sozinho e só chega à noite (F5).

O cuidado em saúde mental no domicílio exige da família maior empenho e preocupação, principalmente com o futuro dos indivíduos em sofrimento psíquico. Portanto, o cuidador de um paciente com doença mental acumula grande sobrecarga de estresse. ${ }^{19}$

Torna-se importante inserir as famílias em grupos de familiares nos serviços comunitários de saúde mental, bem como, prestar esclarecimentos sobre o comportamento, a sintomatologia e o tratamento da enfermidade, sobre 0 uso dos psicofármacos e os efeitos colaterais dos mesmos, realizar visitas domiciliares para conhecer a realidade da família e fazer com que esta não se sinta sozinha. A família deve se sentir segura e capaz de agir de maneira adequada em relação aos sintomas apresentados pelo sujeito em sofrimento psíquico. 20

Uma das entrevistadas afirma participar sempre que possível das atividades sociais do seu familiar, porém, relata constrangimento perante a sociedade devido as condições precárias de higiene que em alguns momentos, a doença mental impõe, conforme evidencia a fala a seguir:

Ele vai para tudo que é lugar comigo, levo ele na igreja, no centro, onde eu vou ele vai junto. Só fico com vergonha de sair com ele quando ele não quer tomar banho porque ele fica vários dias sem banho e não adianta insistir 


\section{NURSING \\ AND HEALTH}

para ele tomar banho porque ele não vai (F5).

Percebe-se a grande preocupação da família relacionada ao cuidado com a higiene e com a aparência pessoal do usuário, aspectos da vida diária que, socialmente, são importantes, pois a aparência pessoal é um cartão de visita nas relações com 0 outro. Isso repercute no aumento da autoestima e na sensação de bem-estar e, consequentemente, facilita a inserção social, pois a pessoa também é considerada pelo cuidado que demonstra consigo mesmo.

Identificou-se através das entrevistas, o quanto é desgastante para a família conviver com 0 sofrimento psíquico, agora tão próximo ao seio familiar, implicando compreender e lidar com comportamentos não convencionais como falar sozinho, a inversão do ciclo de sono, retraimento social, humor inconstante, descuido com a higiene pessoal, os quais terminam por despertar sentimentos ambíguos, como amor, vergonha e angustia. A orientação realizada pelo familiar no cuidado em domicílio ocorre por meio do encontro, da fala e escuta, há vínculo que busca a autonomia, a cidadania e a inclusão social do seu familiar, buscando ainda uma relação de respeito.

Entretanto, é imprescindível a ampliação da rede comunitária de saúde mental e de programas de reabilitação que sejam capazes de oferecer suporte às famílias, proporcionando acolhimento das dificuldades para que de fato a família seja um facilitador importante no processo de reorganização da
ISSN $2236-1987$

assistência psiquiátrica em curso no país.

\section{CONSIDERAÇÕES FINAIS}

Evidenciou-se que os familiares deste estudo percebem sua participação no processo de reabilitação psicossocial de maneiras distintas: alguns frequentando as atividades do CAPS e demais atividades que o usuário desempenha e outros auxiliando no cuidado diário ao indivíduo em sofrimento psíquico. Os resultados apontaram também para tendência ao isolamento do usuário no serviço substitutivo, à medida que todas as suas atividades são relacionadas ao serviço de saúde mental, o que pode estar reproduzindo um modelo de isolamento social.

Alguns entrevistados informam que a socialização do usuário ocorre somente no CAPS, dizendo que estes não participam de atividades fora do âmbito dos serviços, não ocorrendo a reinserção deste indivíduo na comunidade e em outros seguimentos sociais. No entanto, percebemos a partir de algumas falas de familiares demonstrando a independência que alguns sujeitos adquiriram, evidenciando que a passagem pelo serviço substitutivo trouxe benefícios para sua saúde e bem-estar social.

É importante que os profissionais de saúde invistam na autonomia dos indivíduos, contribuindo para o conhecimento do usuário e de sua família acerca dos seus direitos e da proposta da Reforma Psiquiátrica. Isto poderá colaborar com o compromisso da família neste processo, pois esses são atores fundamentais no cenário da reabilitação psicossocial. 


\section{ISSN 2236 - 1987}

Assim, a temática família e saúde mental no cuidado e na ressocialização do sujeito com transtorno mental tornam-se relevantes em face do processo da Reforma Psiquiátrica. Portanto, estudos que abordam o papel da família na convivência com o indivíduo com transtorno psíquico e que promovam discussões dos conceitos de família, saúde mental, transtorno mental e ser humano podem contribuir para cuidados condizentes com as reais necessidades dos indivíduos em sofrimento psíquico.

Acredita-se que mais estudos nessa temática contribuirão na ampliação de dados para instrumentalizar profissionais e familiares na compreensão dos vários aspectos desse fenômeno.

\section{REFERÊNCIAS}

1. Ministério da Saúde (BR). Secretaria Executiva. Secretaria de Atenção à Saúde Mental. Legislação em Saúde Mental: 1990-2004. Brasília; 2004.

2. Behenck A, Silva AD, Humerez DC, Humerez JR, Padilha MICS. A família frente ao processo de tratamento e reinternação do portador de esquizofrenia. Enferm foco. 2011;2(4):210-4.

3. Carvalho MAP, Dias MD, Miranda FAN, Ferreira Filha MO. Contribuições da terapia comunitária integrativa para usuários dos Centros de Atenção Psicossocial (CAPS) do isolamento à sociedade libertadora. Cad saude publica. 2013 out;29(10):2028-38.

4. Ministério da Saúde (BR). Secretaria de Atenção à Saúde. Coordenação Geral de Saúde Mental. Reforma psiquiátrica e política de saúde mental no Brasil. Conferência Regional de Reforma dos Serviços de Saúde Mental: 15 anos depois de Caracas. Brasília; 2005.

5. Guedes AC, Kantorski LP, Coimbra VCC, Olschowski A, Cortes JM, Cantarelli KJ. Tratamento em liberdade: pontos em tensionamento e avanço no centro de atenção psicossocial. Rev enferm UFSM. 2014 $\mathrm{jan} / \mathrm{mar}$;(1):133-43.

6. Pinho LB, Rodrigues J, Kantorski LP, Olschowsky A, Schneider JF. Desafios da prática em saúde mental na perspectiva do modo psicossocial: visão de profissionais de saúde. Rev eletrônica enferm [Internet]. 2012 mar[acesso em 2015 nov 9];14(1):25$32 . \quad$ Disponível em: http://dx.doi.org/10.5216/ree.v14i1. 14352

7. Guedes AC, Kantorski LP, Coimbra VCC, Olschowski A. Estratégias de reinserção social em um centro de atenção psicossocial na visão dos usuários. Cadernos Brasileiros de Saúde Mental. 2013;5(11):147-8.

8. Oliveira MD, Sá MF, Rocha ML. Percepção da sobrecarga familiar nos cuidados ao paciente psiquiátrico crônico. Enferm foco. 2011;2(4):245-7.

9. Silva KVLG, Monteiro ARM. A família em saúde mental: subsídios para 0 cuidado clínico de enfermagem. Rev esc enferm USP. 2011;45(5):1237-42.

10. Ministério da Saúde (BR). Conselho Nacional de Saúde. Resolução 196, de 10 de outubro de 1996: diretrizes e normas regulamentadoras de pesquisa envolvendo seres humanos. Brasília; 1996. 


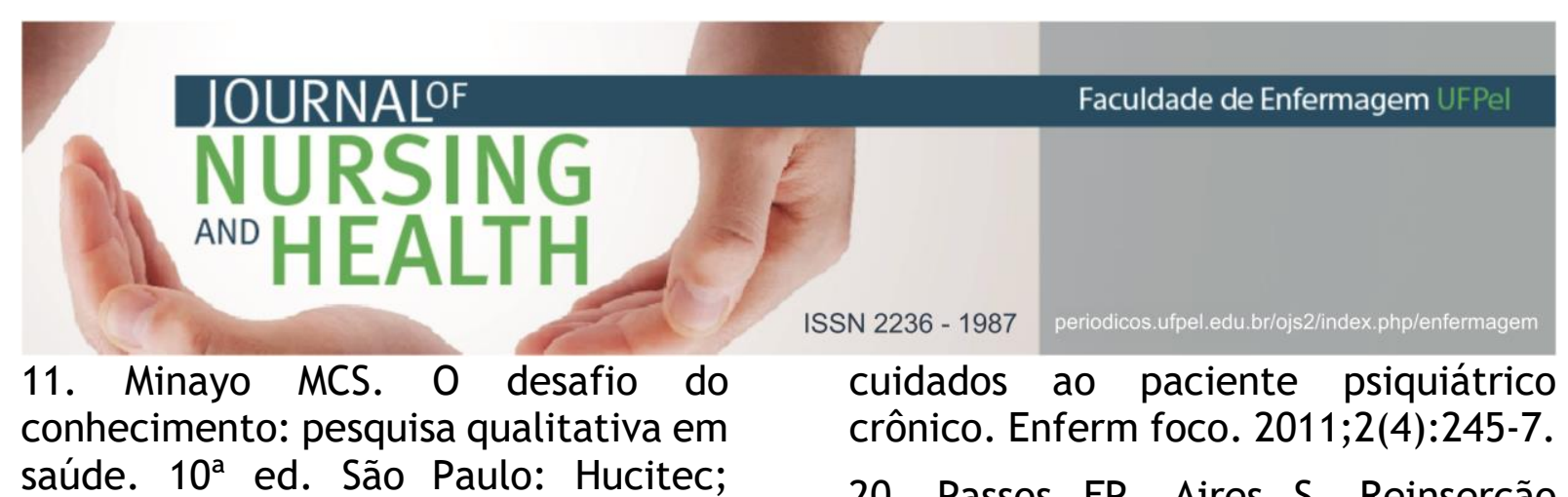
2010.

12. Ministério da Saúde (BR). Portaria 336, de 19 de fevereiro de 2002. Estabelece as modalidades de serviços nos Centros de Atenção Psicossocial (CAPS), definidas por ordem crescente de porte/complexidade e abrangência populacional. Brasília; 2002.

13. Passos FP, Aires S. Reinserção social de portadores de sofrimento psíquico: o olhar de usuários de um Centro de Atenção Psicossocial. Physis. 2013;23(1):13-31.

14. Lavall E. Família e o cuidado de saúde mental no domicílio: estudo avaliativo [dissertação]. Porto Alegre (RS): Universidade Federal do Rio Grande do Sul; 2010.

15. Borba LO, Paes MR, Guimarães AN, Labronici LM, Maftum MA. A família e o portador de transtorno mental: dinâmica e sua relação familiar. Rev esc enferm USP. 2011;45(2):442-9.

16. Cardoso L, Galera SAF. O cuidado em saúde mental na atualidade. Rev esc enferm USP. 2011;45(3):687-91.

17. Nagaoka AP, Furegato ARF, Santos JLF. Usuários de um Centro de Atenção Psicossocial e sua vivência com a doença mental. Rev esc enferm USP. 2011;45(4): 912-7.

18. Vicente JB, Mariano PP, Buriola AA, Paiano M, Waidman MAP, Marcon SS. Aceitação da pessoa com transtorno mental na perspectiva dos familiares. Rev gauch enferm. 2013;34(2):54-61.

19. Oliveira MD, Sá MF, Rocha ML. Percepção da sobrecarga familiar nos 